\title{
An assessment of medical students' proficiency regarding the hazards of radiological examinations on the health of workers and patients: a cross-sectional study from Palestine
}

Ahmed Awadghanem 1,2, Mahmoud Sbaih², Mohammad Hasoon², Zaher Yassin², Ahmad M. Samara², Mosab Maree ${ }^{1,2}$ and Sa'ed H. Zyoud ${ }^{3,4,5^{*}}$ (D)

\begin{abstract}
Background: The use of radiological examination is increasing worldwide. Since radiation exposure can result in many health hazards, medical professionals, as well as medical students, should possess adequate knowledge regarding radiation and its related hazards to protect themselves and the patients. Many studies have assessed medical students' knowledge on this topic, but never in Palestine. In this study, we aimed to examine Palestinian medical students' awareness and knowledge regarding radiological examination modalities and their risks on themselves and their patients.
\end{abstract}

Methods: This was an observational, cross-sectional, population-based study, conducted to assess the awareness of radiation exposure and its risks among Palestinian medical students. An online questionnaire was implemented on medical students at An-Najah National University. A total knowledge score that ranged from 0 to 22 was calculated for each participant, with higher scores indicating better knowledge regarding radiation doses and the related hazards.

Results: Two hundred eighty and seven students participated in our study, with a response rate of $71 \%$. The average knowledge score of the participants was $10.97 \pm 4.31$ out of a maximum of 22 points. Male participants and participants in advanced study years achieved better knowledge scores ( $p$-values were 0.034 and $<0.001$, respectively). Perceived radiology knowledge was significantly associated with the actual knowledge score among the participants ( $p$-value $<0.001$ ). Receiving radiology lectures in fourth and fifth years significantly affected the participants' knowledge score ( $p$-values were $<0.001)$.

(Continued on next page)

\footnotetext{
*Correspondence: saedzyoud@yahoo.com; saedzyoud@najah.edu

${ }^{3}$ Department of Clinical and Community Pharmacy, Department of

Pharmacy, College of Medicine and Health Sciences, An-Najah National University, Nablus 44839, Palestine

${ }^{4}$ Poison Control and Drug Information Center (PCDIC), College of Medicine and Health Sciences, An-Najah National University, Nablus 44839, Palestine Full list of author information is available at the end of the article
}

C C The Author(s). 2020 Open Access This article is licensed under a Creative Commons Attribution 4.0 International License, which permits use, sharing, adaptation, distribution and reproduction in any medium or format, as long as you give appropriate credit to the original author(s) and the source, provide a link to the Creative Commons licence, and indicate if changes were made. The images or other third party material in this article are included in the article's Creative Commons licence, unless indicated otherwise in a credit line to the material. If material is not included in the article's Creative Commons licence and your intended use is not permitted by statutory regulation or exceeds the permitted use, you will need to obtain permission directly from the copyright holder. To view a copy of this licence, visit http://creativecommons.org/licenses/by/4.0/ The Creative Commons Public Domain Dedication waiver (http://creativecommons.org/publicdomain/zero/1.0/) applies to the data made available in this article, unless otherwise stated in a credit line to the data. 
(Continued from previous page)

Conclusions: We found a severe lack of knowledge regarding radiation doses and related risks among medical students. Therefore, we recommend that medical schools update and supplement their curriculum regarding knowledge on radiation.

Keywords: Medical students, Radiological examinations, Radiation hazard, Palestine

\section{Background}

The use of radiological examination is increasing worldwide [1]. The majority of patients being hospitalized nowadays will undergo one or more radiologic examination [2]. In general population, exposure to medical radiation is increasing. For instance, since 1993 the use of computed tomography (CT) scans in the United States had tripled reaching approximately 70 million scans per year [3]. Considering the association between radiation exposure and many health hazards, medical staff should be aware of relevant hazards and the means to protect themselves and the patients [4]. Increased risk of developing cancer is assumed proportional with increased radiation doses in the linear no-threshold (LNT) model [5].

Physicians are responsible for determining whether the patient has to undergo radiologic examination based on risk-benefit analysis [6]. In 2001, Brenner et al. found that lifetime cancer risk was quantitatively correlated with the number of pediatric CT scans [7]. Internationally, about a third of all magnetic resonance imaging (MRI) and CT imaging examinations are considered unwarranted $[8,9]$. Previous studies have shown concerning results indicating that both healthcare professionals and trainees are not sufficiently familiar with radiological dosage and relevant hazards [10-17]. More attention has been directed to physicians' knowledge regarding radiology, which has been frequently rating as inadequate [18]. These findings have prompted increased attention to improving healthcare professionals' knowledge regarding radiological hazards [10-17]. Physicians' knowledge, in particular, should be appropriately evaluated and defects should be traced back to their education at medical schools [19-21].

In Palestine, however, the situation regarding radiological knowledge among medical students has never been examined. Therefore, our aim in the current study was to examine knowledge regarding radiation doses and hazards associated with different diagnostic radiologic tests among Palestinian medical students, as well as their awareness regarding the appropriate use of these tests. The results of this study provide crucial information to guide decisionmakers in their efforts to improve educational plans, as well as clinical guidelines for the optimal use of radiological examination, which will ultimately improve the outcomes of patient care without putting their health or that of the healthcare team in unnecessary jeopardy.

\section{Methods}

\section{Study design}

We conducted an observational study, cross-sectional, to assess the awareness regarding radiation exposure and its risks among Palestinian medical students.

\section{Study setting}

This study was held at An-Najah National University (NNU) in Nablus, Palestine, between September 2019 and January 2020. Participants were enrolled in this study based on the defined inclusion and exclusion criteria.

\section{Study population and sampling technique}

Our target population in this study was undergraduate medical students at NNU. We reached out to 404 students to enroll in this study. The participants were selected using the convenience sampling technique.

\section{Inclusion and exclusion criteria}

In order to be included in the study, the subject had to be a registered student at NNU and had started his or her clinical training (4th, 5th, and 6th years). Both genders were eligible to participate in the study. Participants whose questionnaires were incompletely filled were excluded from the study if the missing data were significant. Those who did not consent to participate in the study were also excluded.

\section{Study tool}

We distributed a questionnaire electronically via an online survey process among NNU medical students. Participation in the survey was voluntary and anonymous. Collection time (time the survey remained open) was 5 months. In order to increase participation in the study, there were two reminders sent to participants. The questionnaire contained multiple-choice questions on radiation doses and associated hazards.

The questionnaire items were in two parts: the first part contained items on socio-demographic characteristics (gender, clinical year, the confidence of knowledge, and radiology education) and the second part, which contained radiation knowledge items, was adapted from a previously used tool [10, 22-25] and supplemented by additional items regarding common radiological modalities. According to the opinions of the relevant experts 
in such types of studies, the questionnaire was slightly modified according to the needs of the sample population. Each question in the second part of the questionnaire has a single correct answer out of four to six options. One mark was given for each correct answer and zero marks for each incorrect or 'I do not know' responses. The overall knowledge score' range was 0-22, with higher scores corresponding to better knowledge on radiation doses and related hazards.

\section{Statistical analysis}

Data analysis was done by SPSS, version 21. All variables were expressed as frequencies and percentages. Means and standard deviations were also presented for continuous variables. Medians and interquartile ranges were also used for variables that did not follow the normal distribution, after testing for that using the KolmogorovSmirnov test. To test for differences between different groups, we used the Kruskal-Wallis test and MannWhitney test, as appropriate. Statistical significance was assumed at $p$-value $<0.05$.

\section{Results}

\section{Demographic and educational characteristics}

Two hundred and eighty-seven (287) students participated in our study, accounting for a response rate of $71 \%$. Overall, $59.2 \%$ of the participants were females. They were distributed in the fourth, fifth, and sixth study year with a roughly balanced ratio $(30.7,32.4$, and $36.9 \%$, respectively). About half of all participants (48.1\%) rated their radiology knowledge as average.

Regarding lectures on radiation knowledge, the percentages of participants who received such lectures during the fourth, fifth, and sixth study year were $36.2,50.5$, and $0.7 \%$, respectively. However, only a minority $(7.3 \%)$ reported receiving lectures on radiation protection specifically. Table 1 summarizes the participants' responses to characteristics items in full.

\section{The participants' knowledge regarding the radiological examination and associated hazards}

Table 2 summarizes the frequencies and percentages of participants who responded correctly to knowledge items. The average knowledge score of the participants was $10.97 \pm 4.31$ (out of 22 points maximum). Notably, most participants failed to estimate the radiation dose that results from different radiological modalities in relation to background radiation (for CXR) or compared to the dose received from one CXR (for all other modalities). Only items asking about which radiological modalities used X-ray and another item asking about the most susceptible group to radiation were answered correctly by more than half the participants.
Table 1 Demographic and educational characteristics of the participants

\begin{tabular}{ll}
\hline Characteristic & Frequency (\%); $\mathbf{N = 2 8 7}$ \\
\hline Gender & $117(40.8)$ \\
Male & $170(59.2)$ \\
Female & \\
Clinical year & $88(30.7)$ \\
4th year & $93(32.4)$ \\
5th year & $106(36.9)$ \\
6th year &
\end{tabular}

Self-perceived radiology knowledge compared to other subjects

$\begin{array}{ll}\text { Excellent } & 5(1.7) \\ \text { Good } & 83(28.9) \\ \text { Average } & 138(48.1) \\ \text { Poor } & 57(19.9) \\ \text { No knowledge } & 4(1.4)\end{array}$

Received radiology lectures as a part of the anatomy course

Yes $28(9.8)$

No 259 (90.2)

Received radiology lectures as a part of a clinical skills course

Yes 137 (47.7)

No 150 (52.3)

Received Radiology lectures during 4th clinical year

Yes 104 (36.2)

No $183(63.8)$

Received Radiology lectures during 5th clinical year

Yes 145 (50.5)

No $142(49.5)$

Received Radiology lectures during 6th clinical year

$\begin{array}{ll}\text { Yes } & 2(0.7) \\ \text { No } & 285(99.3)\end{array}$

Received education on protection from radiation

Yes 21 (7.3)

No $266(92.7)$

Relationship of participants' knowledge scores and their demographic and educational characteristics

Table 3 presents the findings of comparing knowledge scores between participants in different groups based on their characteristics. We found that male participants achieved a significantly higher knowledge score compared to female participants $(p$-value $=0.034)$. We also found a significant positive correlation between the clinical year participants were in and their knowledge scores ( $p$-value< 0.001 ). Perceived radiology knowledge was significantly associated with the actual knowledge score among the participants $(p$-value< 0.001$)$. Receiving radiology lectures in fourth and fifth years, but not in the sixth year, 
Table 2 Frequencies and percentages of participants who answered correctly for each of the knowledge items

\begin{tabular}{|c|c|}
\hline Knowledge item* & Frequency (\%) \\
\hline \multicolumn{2}{|l|}{ 1. Which of the following modalities do you think uses X-rays? } \\
\hline a. MRI (no) & $234(81.5)$ \\
\hline b. Chest X-ray (yes) & $282(98.3)$ \\
\hline c. Ultrasound (no) & $251(87.5)$ \\
\hline d. CT (yes) & $198(69.0)$ \\
\hline e. Conventional fluoroscopy (yes) & $194(67.6)$ \\
\hline f. Mammography (yes) & $181(63.1)$ \\
\hline g. Angiography (yes) & $155(54.0)$ \\
\hline $\begin{array}{l}\text { 2. In a chest } \mathrm{X} \text {-ray, the radiation dose is the same as natural background radiation received in how long? } \\
\text { (less than } 1 \text { week) }\end{array}$ & $28(9.8)$ \\
\hline \multicolumn{2}{|l|}{ 3. For each of the following modalities, the radiation dose is approximately the same as how many chest $x$-rays? } \\
\hline a. Ultrasound of abdomen (zero) & $131(45.6)$ \\
\hline b. CT of the abdomen (300-1000) & $63(22.0)$ \\
\hline c. MRI of the abdomen (zero) & $114(39.7)$ \\
\hline d. Abdominal X-ray (20-50) & $51(17.8)$ \\
\hline e. Barium swallow (20-50) & $33(11.5)$ \\
\hline f. MRI of the spine (zero) & $93(32.4)$ \\
\hline 4. Which of the following involves the highest radiation exposure for the patient? (plain film of the abdomen) & $82(28.6)$ \\
\hline 5. Which of the following groups is the most sensitive to radiation? (children) & $240(83.6)$ \\
\hline 6. Which organ is the least sensitive to radiation? (kidney) & $131(45.6)$ \\
\hline 7. Which of the following modalities is responsible for most of the radiation received by the general population? (CT) & $89(31.0)$ \\
\hline \multicolumn{2}{|l|}{ 8. For each of the following modalities, do you think it increases the lifetime risk of developing cancer? } \\
\hline a. MRI (definitely no) & $103(35.9)$ \\
\hline b. Chest X-ray (definitely yes) & $64(22.3)$ \\
\hline c. Ultrasound (definitely no) & $150(52.3)$ \\
\hline d. CT (definitely yes) & $109(38.0)$ \\
\hline
\end{tabular}

* The correct answer is indicated between parentheses after each knowledge item

significantly affected the participants' knowledge score ( $p$ values were $<0.001$ for lectures during the fourth and fifth year and 0.426 for the sixth year).

\section{Discussion}

In this study, we examined, for the first time in Palestine, knowledge levels regarding radiation exposure and related hazards among medical students. Our findings indicate a serious knowledge gap, as evidenced by medical students' mean radiation knowledge score (10.97 \pm 4.31 out of a 22-point maximum).

The results of this study are in concordance with reports from the relevant literature, which indicated a gap in vital radiation knowledge among medical students. These studies are stemming from the need to prepare medical students for their future duties as physicians how should understand the risks and benefits of different radiological examination tools in order to optimally use them. So far, the results of such studies, including the current study, have been concerning. Numerous studies have been conducted in recent years among medical students and physicians for that our purpose [17, 18, 22, 23, 26-33]. Previous studies have shown concerning results indicating that both healthcare professionals and trainees are not sufficiently familiar with radiological dosage and relevant hazards [10-17].

Only a minority of the participating students demonstrated sufficient knowledge regarding the radiation dose in a single chest $x$-ray (CXR), a very common imaging modality. This is a particularly worrying finding considering that CXR knowledge is considered basic and essential knowledge for understanding risks associated with other imaging modalities in perspective.

In our sample, male students scored higher than female students on radiation knowledge. This finding may be caused by an uneven encouragement for male students to pursue radiology education and career paths that their female counterparts and further investigation in this area are required. The finding that medical students in more advanced study years achieved higher 
Table 3 Relationship between the participants' demographic and educational characteristics and their knowledge scores

\begin{tabular}{|c|c|c|}
\hline Characteristic & Knowledge score a Median [Q1-Q3] & $P$-value* \\
\hline \multicolumn{3}{|l|}{ Gender } \\
\hline Male & $12.00[8.00-15.00]$ & $0.034^{b}$ \\
\hline Female & $10.25[7.00-13.63]$ & \\
\hline \multicolumn{3}{|l|}{ Clinical year } \\
\hline 4th year & 8.25 [6.00-10.50] & $<0.001^{c}$ \\
\hline 5th year & $10.50[8.50-14.00]$ & \\
\hline 6th year & $13.25[10.00-16.00]$ & \\
\hline \multicolumn{3}{|c|}{ Self-perceived radiology knowledge compared to other subjects } \\
\hline Excellent & $10.50[8.50-11.75]$ & $<0.001^{c}$ \\
\hline Good & $11.50[8.00-15.00]$ & \\
\hline Average & $12.00[9.00-15.13]$ & \\
\hline Poor & $8.00[5.25-10.00]$ & \\
\hline No knowledge & $5.25[2.50-8.00]$ & \\
\hline
\end{tabular}

Received radiology lectures as a part of the anatomy course

$\begin{array}{lll}\text { Yes } & 11.25[8.25-15.38] & 0.412^{b} \\ \text { No } & 10.50[8.00-14.00] & \end{array}$

Received radiology lectures as a part of a clinical skills course

Yes $\quad 11.50[8.50-14.50]$

$0.110^{b}$

No $\quad 10.00[7.50-14.00]$

Received Radiology lectures during 4th clinical year

Yes $\quad 9.00$ [6.50-13.00]

No $\quad 12.00[9.00-15.00]$

$<0.001^{b}$

Received Radiology lectures during 5th clinical year

$$
\begin{array}{ll}
\text { Yes } & 12.50[9.50-15.50] \\
\text { No } & 9.00[6.00-13.00]
\end{array}
$$

Received Radiology lectures during 6th clinical year

$\begin{array}{ll}\text { Yes } & 8.00[3.00-\mathrm{NA}] \\ \text { No } & 10.50[8.00-14.25]\end{array}$

Received education on protection from radiation

Q1-Q3 Quartile 3, Quartile 3, NA not available

* Significant p-values are in bold

a The overall knowledge score' range was $0-22$, with higher scores

corresponding to better knowledge on radiation doses and related hazards

${ }^{\mathrm{b}}$ Statistical significance of differences calculated using the Mann-Whitney

$\mathrm{U}$ test

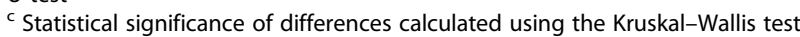

knowledge scores may point to a positive accumulation of knowledge throughout medical school, but considering the low average knowledge score regarding radiation, this effect is still insufficient for students to gain the appropriate level of relevant knowledge. These findings seem to be consistent with a report from Australia which found that $55.3 \%$ of medical students were females, but only $33.0 \%$ of trainees in radiology were females [34], and $26.5 \%$ of the radiologist workforce was female [35]. To encourage female students to select radiology as an appealing career option, more research needs to find challenges and solutions.

Another interesting finding in our study was that students who reported having excellent radiological knowledge achieved lower knowledge scores than those how rated their knowledge as average. This finding could point to a lack of recognition of the existing knowledge gap among the students. This is consistent with another study that reported a negative correlation between perceived knowledge and achieved knowledge score [17]. In contrast to other studies, knowledge related to MRI and US were noticeable good within our sample [32]. This could be due to the nature of the students' curriculum and the topics it focuses on. On the other hand, knowledge related to CT scan radiation was inadequate. This is particularly worrying concerning that CT is considered a major source of radiation exposure being responsible for $70 \%$ of medical radiation dose [36].

\section{Strengths and limitations}

A major limitation of this study was its cross-sectional design, which determined associations but could not address causality. Also, the convenience sampling method may have limited the generalizability of our results. Another limitation was the single-center setting of the study.

On the other hand, this was the first study of its kind in Palestine, and it provided important information regarding radiation awareness. Additionally, we used a very cost-efficient data collection method and, at the same time, included a large sample size, which increased the representation of our target population.

\section{Conclusions and recommendations}

In conclusion, we found a severe lack of knowledge regarding radiation doses and related risks among medical students in Palestine. Such a low level of knowledge calls for a reconsideration of the current curriculum of medical education regarding radiation knowledge and its relevance. Our results also showed that medical students specifically underestimated radiation risks associated with CT scans, and demonstrated little knowledge about $\mathrm{X}$-ray doses associated with radiological examination tools. We highly recommend redesigning certain courses and lectures in medical schools' curriculum to include more information on radiation doses, associated risks, and radiation protection strategies. We also recommend using better tools for assessing students' knowledge prior to participating in the medical field to avoid the overuse of ionizing radiation modalities. Finally, we recommend conducting multi-centric studies that assess radiation knowledge in order to explore this problem on a larger scale. 


\section{Abbreviations}

NNU: An-Najah National University; CXR: Chest X-ray; MRI: Magnetic resonance imaging; CT: Computed tomography; LNT: linear no-threshold; IRB: Institutional Review Board

\section{Acknowledgments}

Not applicable.

\section{Authors' contributions}

MS, MH, and ZY performed data collection and analysis, reviewed the literature and contributed to drafting the manuscript. AS performed data analysis, reviewed the literature, contributed to interpreting the data, and assisted in drafting the manuscript. AA and MM contributed to the conception and design of the study and interpreting the data. SZ conceptualized and designed the study; supervised, coordinated, and was responsible for the integrity of the data and the accuracy of its analysis; he critically reviewed the results' interpretation, and assisted in the final writeup. All authors read the final manuscript and approved it.

\section{Funding}

None.

\section{Availability of data and materials}

The datasets used and/or analyzed in this study will be made available by the corresponding author upon reasonable request.

\section{Ethics approval and consent to participate}

The research started after obtaining IRB approval from An-Najah National University, and the questionnaire displayed a written informed consent for students to read and voluntarily accept before they could more to the question items.

\section{Consent for publication}

Not applicable.

\section{Competing interests}

The authors declare that they have no conflict of interest.

\section{Author details}

'Department of Radiology, An-Najah National University Hospital, Nablus 44839, Palestine. 'Department of Medicine, College of Medicine and Health Sciences, An-Najah National University, Nablus 44839, Palestine. ${ }^{3}$ Department of Clinical and Community Pharmacy, Department of Pharmacy, College of Medicine and Health Sciences, An-Najah National University, Nablus 44839 , Palestine. ${ }^{4}$ Poison Control and Drug Information Center (PCDIC), College of Medicine and Health Sciences, An-Najah National University, Nablus 44839, Palestine. ${ }^{5}$ Clinical Research Center, An-Najah National University Hospital, Nablus 44839, Palestine.

Received: 23 June 2020 Accepted: 24 November 2020

\section{Published online: 03 December 2020}

\section{References}

1. World Health Organization. Radiation safety culture in medicine. 2020 https://www.who.int/ionizing_radiation/medical_radiation_exposure/ culture/en/ (accessed October 12 2020)

2. Smith-Bindman $\mathrm{R}$, Miglioretti DL, Larson EB. Rising use of diagnostic medical imaging in a large integrated health system. Health Aff (Millwood). 2008; 27(6):1491-502.

3. Mettler FA Jr, Thomadsen BR, Bhargavan M, Gilley DB, Gray JE, Lipoti JA, McCrohan J, Yoshizumi TT, Mahesh M. Medical radiation exposure in the U. S. in 2006: Preliminary results. Health Phys. 2008;95(5):502-7.

4. Goodman TR, Mustafa A, Rowe E. Pediatric CT radiation exposure: where we were, and where we are now. Pediatr Radiol. 2019:49(4):469-78.

5. International Commission on Radiological Protection. The 2007 Recommendations of the international commission on radiological protection. ICRP publication 103. Ann ICRP. 2007;37(2-4):1-332.

6. Vom J, Williams I. Justification of radiographic examinations: what are the key issues? J Med Radiat Sci. 2017;64(3):212-9.

7. Brenner D, Elliston C, Hall E, Berdon W. Estimated risks of radiation-induced fatal cancer from pediatric CT. AJR Am J Roentgenol. 2001;176(2):289-96.
8. Oikarinen $H$, Meriläinen $S$, Pääkkö $E$, Karttunen A, Nieminen MT, Tervonen O. Unjustified CT examinations in young patients. Eur Radiol. 2009;19(5):1161-5

9. Sobiecka A, Bekiesinska-Figatowska M, Rutkowska M, Latos T, Walecki J. Clinically unjustified diagnostic imaging - a worrisome tendency in Today's medical practice. Pol J Radiol. 2016:81:325-30.

10. Soye JA, Paterson A. A survey of awareness of radiation dose among health professionals in Northern Ireland. Br J Radiol. 2008;81(969):725-9.

11. Wong CS, Huang B, Sin HK, Wong WL, Yiu KL, Yiu C, Ching T. A questionnaire study assessing local physicians, radiologists and interns' knowledge and practice pertaining to radiation exposure related to radiological imaging. Eur J Radiol. 2012;81(3):e264-8.

12. Lee RK, Chu WC, Graham CA, Rainer TH, Ahuja AT. Knowledge of radiation exposure in common radiological investigations: a comparison between radiologists and non-radiologists. Emerg Med J. 2012;29(4):306-8.

13. Krille L, Hammer GP, Merzenich H, Zeeb H. Systematic review on physician's knowledge about radiation doses and radiation risks of computed tomography. Eur J Radiol. 2010;76(1):36-41.

14. Foley SJ, Evanoff MG, Rainford LA. A questionnaire survey reviewing radiologists' and clinical specialist radiographers' knowledge of CT exposure parameters. Insights Imag. 2013:4(5):637-46.

15. Ramanathan $\mathrm{S}$, Ryan J. Radiation awareness among radiology residents, technologists, fellows and staff: where do we stand? Insights Imag. 2015: 6(1):133-9.

16. Paolicchi F, Miniati F, Bastiani L, Faggioni L, Ciaramella A, Creonti I, Sottocornola C, Dionisi C, Caramella D. Assessment of radiation protection awareness and knowledge about radiological examination doses among Italian radiographers. Insights Imag. 2016;7(2):233-42.

17. Faggioni L, Paolicchi F, Bastiani L, Guido D, Caramella D. Awareness of radiation protection and dose levels of imaging procedures among medical students, radiography students, and radiology residents at an academic hospital: results of a comprehensive survey. Eur J Radiol. 2017:86:135-42.

18. Scali E, Mayo J, Nicolaou S, Kozoriz M, Chang S. Senior medical students' awareness of radiation risks from common diagnostic imaging examinations. Can Med Educ J. 2017:8(4):e31-41.

19. Cole P, Hallard R, Broughton J, Coates R, Croft J, Davies K, Devine I, Lewis C Marsden $\mathrm{P}$, Marsh A, et al. Developing the radiation protection safety culture in the UK. J Radiol Prot. 2014:34(2):469-84.

20. Coldwell T, Cole P, Edwards C, Makepeace J, Murdock C, Odams H, Whitcher $\mathrm{R}$, Willis $\mathrm{S}$, Yates $\mathrm{L}$. The advantages of creating a positive radiation safety culture in the higher education and research sectors. J Radiol Prot. 2015; 35(4):917-33.

21. Singh RK, McCoubrie P, Burney K, Miles JA. Teaching medical students about radiation protection--what do they need to know? Clin Radiol. 2008; 63(12):1344-9.

22. Shiralkar S, Rennie A, Snow M, Galland RB, Lewis MH, Gower-Thomas K. Doctors' knowledge of radiation exposure: questionnaire study. BMJ. 2003; 327(7411):371-2

23. Zhou GZ, Wong DD, Nguyen LK, Mendelson RM. Student and intern awareness of ionising radiation exposure from common diagnostic imaging procedures. J Med Imag Radiat Oncol. 2010;54(1):17-23.

24. McCusker MW, de Blacam C, Keogan M, McDermott R, Beddy P. Survey of medical students and junior house doctors on the effects of medical radiation: is medical education deficient? Ir J Med Sci. 2009;178(4):479-83.

25. O'Sullivan J, O'Connor OJ, O'Regan K, Clarke B, Burgoyne LN, Ryan MF, Maher MM. An assessment of medical students' awareness of radiation exposures associated with diagnostic imaging investigations. Insights Imag. 2010;1(2):86-92

26. Abuelhia E. Awareness of ionizing radiation exposure among junior doctors and senior medical students in radiological investigations. J Radiol Prot. 2017;37(1):59-67.

27. Uri IF. Lack of radiation awareness among referrers: implications and possible solutions. Int J Clin Pract. 2012;66(6):574-81.

28. Teferi S, Zewdeneh D, Bekele S. Pediatric Residents' and medical Interns' awareness about pediatric ionizing radiation dose from computed tomography and its associated risks in tertiary Hospital in Ethiopia. Ethiop J Health Sci. 2018;28(4):383-92

29. Sin HK, Wong CS, Huang B, Yiu KL, Wong WL, Chu YC. Assessing local patients' knowledge and awareness of radiation dose and risks associated with medical imaging: a questionnaire study. J Med Imag Radiat Oncol. 2013;57(1):38-44. 
30. Hadelsberg UP, Harel R. Hazards of ionizing radiation and its impact on spine surgery. World Neurosurg. 2016;92:353-9.

31. Al-Rammah TY. CT radiation dose awareness among paediatricians. Ital J Pediatr. 2016;42(1):77.

32. Kada S. Awareness and knowledge of radiation dose and associated risks among final year medical students in Norway. Insights Imag. 2017;8(6):599605.

33. Furmaniak KZ, Kolodziejska MA, Szopinski KT. Radiation awareness among dentists, radiographers and students. Dentomaxillofac Radiol. 2016;45(8): 20160097.

34. Ip SW, Ko HS, Applegate KE. Factors influencing career choices in radiology trainees in Queensland, Australia. J Med Imaging Radiat Oncol. 2010;54(2): 93-9.

35. The Royal Australian and New Zealand College of Radiologists (RANZCR). 2016 workforce survey report australia. 2018. https://www.ranzcr.com/ documents/4624-2016-clinical-radiology-workforce-census-report-australia/ file (accessed October 12 2020).

36. Manssor E, Abuderman A, Osman S, Alenezi SB, Almehemeid S, Babikir E, Alkhorayef M, Sulieman A. Radiation doses in chest, abdomen and pelvis CT procedures. Radiat Prot Dosim. 2015;165(1-4):194-8.

\section{Publisher's Note}

Springer Nature remains neutral with regard to jurisdictional claims in published maps and institutional affiliations.

Ready to submit your research? Choose BMC and benefit from:

- fast, convenient online submission

- thorough peer review by experienced researchers in your field

- rapid publication on acceptance

- support for research data, including large and complex data types

- gold Open Access which fosters wider collaboration and increased citations

- maximum visibility for your research: over $100 \mathrm{M}$ website views per year

At $\mathrm{BMC}$, research is always in progress.

Learn more biomedcentral.com/submissions 